\title{
Creep strains on reinforced concrete columns
}

\section{Deformações por fluência em pilares de concreto armado}

\author{
E. L. MADUREIRA a \\ edmadurei@yahoo.com.br \\ T. M. SIQUEIRA ${ }^{\text {a }}$ \\ tiagosiqueira12@hotmail.com \\ E. C. RODRIGUES a \\ edmilsoncrodrigues@gmail.com
}

\begin{abstract}
A concrete element when kept under sustained load presents progressive strain over time, associated to the creep. In reinforced concrete columns, such deformations cause the stress increase in the steel bars of the reinforcement and may induce the material to undergo the yielding phenomenon. The pioneering formulations about the creep effect, developed on the base of creep coefficient, are applicable, especially, when the stress magnitude remains constant. Its application to reinforced concrete members, which exhibits change in stress magnitude, requires simplifications of which result the memory models, which have the disadvantage of requiring the storage of the stress history. To overcome the difficulties related to the excessive demand for computer memory, State models have been developed that dispense such robustness of storage. The subject of this work is the analysis of creep deformations in reinforced concrete columns on the base of a state model fixing its physical parameters from results obtained through the NBR 6118/07 formulation. The results showed that, in the elapse of the phenomenon, occurs stresses transfer from the concrete mass to the reinforcement steel bars which, in turn, have the effect of restrain the creep strains, confirming, in some cases, an imminent material yielding condition.
\end{abstract}

Keywords: reinforced concrete, column, creep, simulation.

\section{Resumo}

Um elemento de concreto quando mantido sob tensão apresenta deformação progressiva no decorrer do tempo, aditiva à deformação imediata ao carregamento. Em pilares de concreto armado, as deformações por fluência promovem o acréscimo de tensões nas barras de aço, podendo induzir o material a experimentar o escoamento. As formulações pioneiras do efeito de fluência, desenvolvidas com base no coeficiente de fluência, são aplicáveis, sobretudo, quando as tensões se mantêm constantes. Sua aplicação a elementos de concreto armado, que apresentam variações de tensões, requer simplificações das quais resultam os modelos de memória, que têm a desvantagem de exigir o armazenamento do histórico de tensões. Para suplantar as dificuldades ligadas à excessiva demanda de memória de computador, foram desenvolvidos os modelos de estado que dispensam tal robustez de armazenamento. O objetivo deste trabalho é a análise das deformações por fluência em pilares de concreto armado, realizada com base em um modelo de estado, com parâmetros fixados a partir da formulação da NBR 6118/07. Os resultados obtidos revelaram que, no decorrer do fenômeno, verifica-se a transferência de esforços do concreto para as barras da armadura de aço, que por sua vez exercem o efeito de contenção das deformações correlatas, confirmando-se, em alguns casos, o estabelecimento de uma condição de iminente escoamento do material.

Palavras-chave: concreto armado, pilar, fluência, simulação. 


\section{Introduction}

The state of stresses due to sustained load, promotes strains in concrete members which progresses over time, characterizing the phenomenon known as creep.

Such kind of deformations results, particularly, from the viscous behaviour associated to the adsorbed water layer at the cement grains surface, in the hardened concrete (McGREGOR, 1997), apud [8].

The creep deformations are more pronounced in the first months of the structure lifetime, when develop under higher rates. It can extend for periods of time up to ten years, although in more advanced stages, it evolves over modest rates. There are cases in which the creep deformations can take magnitudes greater than three times the deformation at the instant of loading, inducing structural displacements of similar magnitude [8].

Among the relevant factors that influence the creep deformation it may include environmental moisture, the ratio of the applied stress to the concrete strength, and the reinforcement.

In the case of reinforced concrete members, the deformations due to creep can modify significantly the stress fields in their constituents. In columns, specifically, it can promote the stress reduction on the mass of the concrete and the stress increase in the steel bars, which can induce the latter to experience the yielding phenomenon.

The pioneering formulations for creep deformation modelling were developed from the creep coefficient concept. They are applied, in particular, to elements for which the stresses on the concrete remain constant over time. Their adequacy for reinforced concrete members, which exhibit stress variations during the phenomenon, depends on the application of simplifier artifices that result on memory models. These kinds of formulations are so named because they demand, in its calculation, the history of stresses storage, resulting in large-scale storage amount that can become the modelling unfeasible.

In order to overcome the difficulties related to the storage robustness, it was developed the state models that provide the use, exclusively, of the stresses at the moment before the considered instant.

The aim of this work is the simulation of the creep strain on reinforced concrete columns, based on a state model, whose parameters were fixed from results obtained by NBR 6118/07 formulation, focused, above all, for the analysis of the reinforcement and moisture rate influences on the phenomenon.

\section{Modelling}

\subsection{Concrete response to loading}

The numerical analysis was performed according to incremental iterative procedure and finite element approach. The adopted mathematical modelling is based on the orthotropic nonlinear formulation proposed by Kwak and Filippou [7] in plane state of stress, from which the constitutive matrix elements to be used are defined through equations similar to those employed in uniaxial state of stress, however, taking as a reference, the equivalent deformations " $\varepsilon_{\mathrm{ei}}$ ", that, for every one of the principal directions are given by:

$$
\varepsilon_{e i}=\varepsilon_{i}+D_{i j} \varepsilon_{j} / D_{i i}
$$

The "i" and "j" indexes refer to principal plane direction. The " $D_{i j}$ " parameters represent the constitutive matrix elements.

For the simulation of concrete in compression it was adopted the constitutive relationships proposed by Hognestad [3], presented in the form:

$$
\begin{aligned}
& \sigma_{i}=\frac{2 . \sigma_{i p}}{\varepsilon_{i p}}\left(1-\frac{\varepsilon_{e i}}{2 . \varepsilon_{i p}}\right) \cdot \varepsilon_{e i} \text { for } \varepsilon_{\mathrm{ip}}<\varepsilon_{\mathrm{ei}}<0 ; \mathrm{e} \\
& \sigma_{i}=\sigma_{i p}\left(1-\frac{3}{20} \frac{\varepsilon_{e i}-\varepsilon_{i p}}{\varepsilon_{c u}-\varepsilon_{i p}}\right) \text { for } \varepsilon_{\mathrm{cu}}<\varepsilon_{\mathrm{ei}}<\varepsilon_{\mathrm{ip}} .
\end{aligned}
$$

The parameters " $\sigma_{i p}$ " and " $\varepsilon_{i p}$ " represent the concrete peak stress and its correspondent strain beyond every "i" principal direction, and " $\varepsilon_{\mathrm{cu}}$ " is the ultimate strain. These equations represent the hardening and softening branches, $\mathbf{O A}$ and $\mathbf{A B}$, respectively, of the curve in figure 1.

For the representation of the concrete behaviour in tensile stress, was adopted the smeared crack model, whose advantages are consider the continuity of the displacement fields, and to dispense modifications of topological character in finite element mesh, in the course of the processing inherent to its stages of calculation, as shown in [7].

In addition, it was adopted the multidirectional cracking pattern, represented by a system of mutually orthogonal cracks, in which the inclination of their plans depends on the current state of stress and may change according the loading stage.

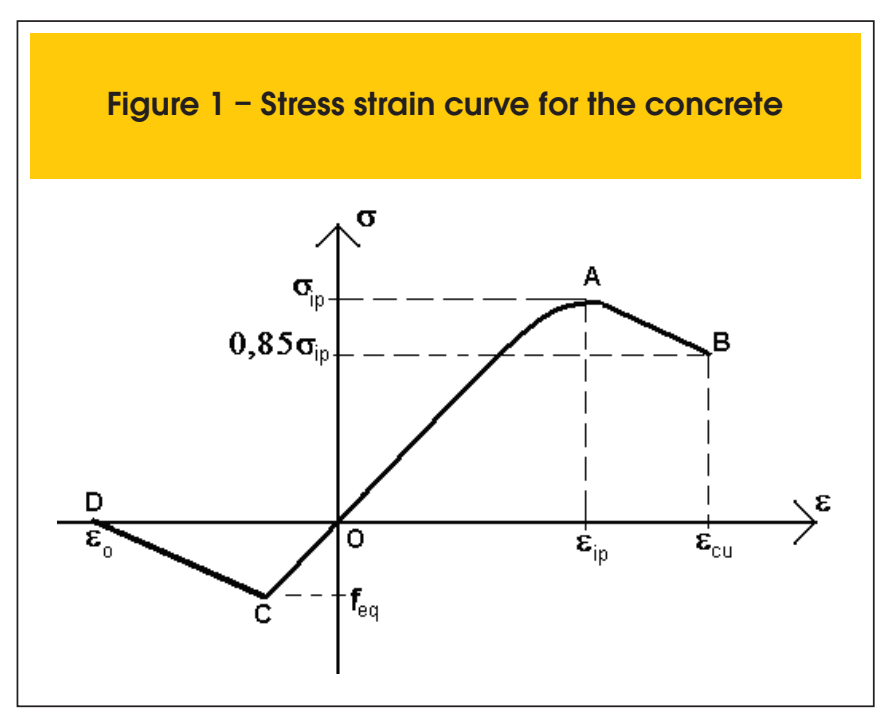


The concrete behaviour, for deformations lower than that corresponding to the tensile strength, segment $\mathrm{OC}$ of the curve in figure 1 , is considered to be linear elastic. For deformations of higher magnitude, its behaviour is plastic with softening, being represented by segment $C D$, defined, even, as the value of the ultimate tensile deformation, " $\varepsilon_{o}$ ".

The cracked concrete ultimate deformation, assuming that the stiffness is uniform on the entire finite element, would be given by:

$$
\varepsilon_{o}=\frac{2 . G_{f}}{f_{t}}
$$

Where the "f." e "G." parameters represent, respectively, the tensile strength and the fracturing energy per unit of area of concrete, the latter defined according to the CEB-FIP model code 1990 criteria [2] However, the cracking pattern promotes disturbance on the uniformity and continuity of the mass of concrete, inducing variation of mechanical properties within the finite element. The larger the size of the finite element, the greater will be the variation of stiffness in its interior. In order to compensate the errors arising from such variations, in this work, for elements greater than $75 \mathrm{~mm}$ length, it is used the proposed resource by Kwak and Filippou [7], by setting the ultimate tensile strain from:

$$
\varepsilon_{o}=\frac{2 \cdot G_{f} \cdot \ln (0,075 / b)}{f_{t} \cdot(0,075-b)}
$$

to which "b" is the finite element dimension expressed in meters. The adopted concrete deformation module is the secant modulus, " $E_{c}$ ", that is obtained from:

$$
E_{c}=0,85 E_{0}
$$

Where the " $E_{0}$ " parameter is the initial deformation modulus, that is expressed according to [1], on the form of equation:

$$
E_{0}=5600 \sqrt{f_{c k}} \quad(M P a)
$$

In which the " $f_{c k}$ " parameter is the concrete characteristic compressive strength.

The concrete ultimate stresses are defined from the failure envelope proposed by Kupfer and Gerstle [6], figure 2, whose analytical representation in biaxial compression state is:

$$
\left(\beta_{1}+\beta_{2}\right)^{2}-\beta_{2}-3.65 \beta_{1}=0
$$

where, $\beta_{1}=\sigma_{1} / f_{c}$ and $\beta_{2}=\sigma_{2} / f_{c}$ are the principal stresses with $0>\sigma_{1}>\sigma_{2}$. " $f_{c}$ " is the concrete uniaxial compressive strength. If in equation 7 it is considered $\alpha=\sigma_{1} / \sigma_{2}$, the concrete peak stresses, on the principal directions, will be given by:

$$
\sigma_{2 c}=\frac{1+3.65 . \alpha}{(1+\alpha)^{2}} f_{c} \text { and } \sigma_{l c}=\sigma_{c u}=\alpha . \sigma_{2}
$$

The strains related to peak stresses in biaxial compression state, " $\varepsilon_{2 p}$ " and " $\varepsilon_{1 \mathrm{p}}$ ", according to [7], are obtained from the expressions:

$$
\begin{aligned}
& \varepsilon_{2 p}=\varepsilon_{c o}\left(3 \beta_{2}-2\right) \text { and } \\
& \varepsilon_{1 p}=\varepsilon_{c o}\left(-1.6 \beta_{1}^{3}+2.25 \beta_{l}^{2}+0.35 \beta_{1}\right)
\end{aligned}
$$

where $\beta_{1}=\frac{\sigma_{1 p}}{f_{c}}$ and $\beta_{2}=\frac{\sigma_{2 p}}{f_{c}}$. The parameter " $\varepsilon_{\mathrm{co}}$ " is the corresponding deformation to the stress peak compression in uniaxial state of stress.

For concrete subjected to biaxial state of stress, it was adopted the constitutive relationship on incremental form proposed by Desai and Siriwardance, (apud [7]), written by equation 10 .

\begin{tabular}{|l|l|ccc|}
$d \sigma_{1}$ \\
$d \sigma_{2}$ \\
$d \tau_{12}$
\end{tabular}$\left|=\frac{1}{1-v^{2}}\right| \begin{array}{ccc}E_{1} & v \sqrt{E_{1} E_{2}} & 0 \\
v \sqrt{E_{1} \cdot E_{2}} & E_{2} & 0 \\
0 & 0 & \left(1-v^{2}\right) . G \mid\end{array}\left|\begin{array}{c}d \varepsilon_{1} \\
d \varepsilon_{2} \\
d \gamma_{12}\end{array}\right|$ (10)

Figure 2 - Ultimate stress envelop for concrete in biaxial state of stresses

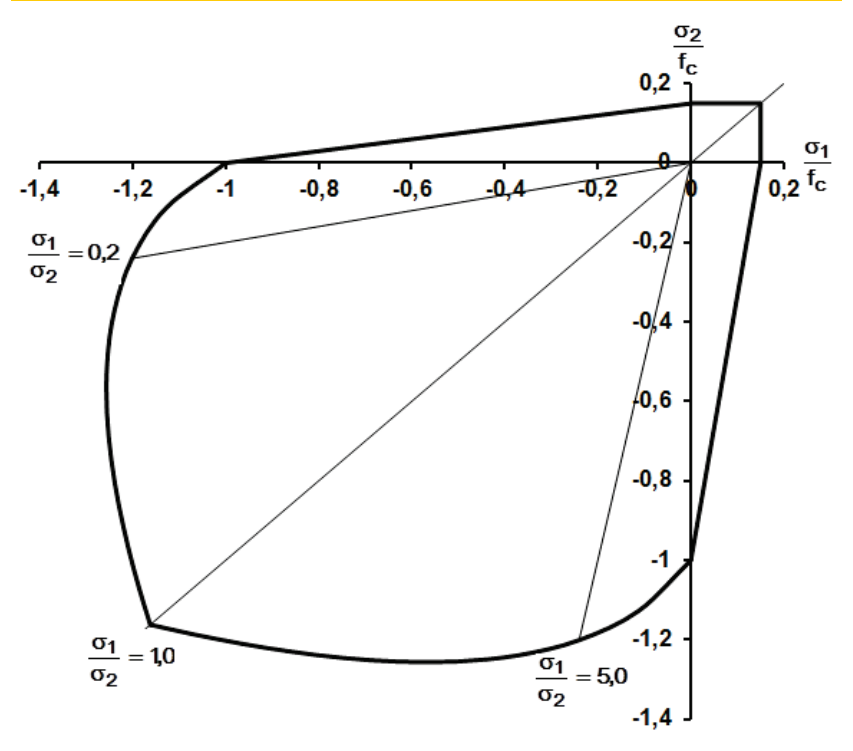


On equation 10 " $d \sigma_{1}$ ", "d $\sigma_{2}$ " e " $\mathrm{dr}_{12}$ " are the stress increments on the principal directions. The "E,'s" parameters are the tangent deformation modules relating to such directions and " $v$ " is the Poisson's ratio. The "G" parameter is the transversal deformation module that is given by:

$$
\left(1-v^{2}\right) \cdot G=0.25\left(E_{1}+E_{2}-2 v \sqrt{E_{1} \cdot E_{2}}\right)
$$

In this analysis were adopted the quadratic approximation isoparametric finite elements.

The mass of concrete region is represented by plane eight-node quadrilateral elements $\mathbf{Q 8}$, as shown in figure 3.a.

\subsection{Steel response to loading}

The steel behaviour is considered as elastic perfectly plastic. Due to the great transverse flexibility of the reinforcement steel bars, only axial stiffness is considered, and then they are simulated by bar three-node elements L3, figure 3.b. In this way, the related stiffness matrix " $K$ " is expressed by:

$$
K=\frac{2 A E}{L}\left[\begin{array}{rrr}
1 & 0 & -1 \\
0 & 1 & -1 \\
-1 & -1 & 2
\end{array}\right]
$$

where the parameter " $E$ " represents the steel Young's modulus, which is considered equal to $210,000 \mathrm{MPa}$. "A" is the reinforcement cross section area, while " $L$ " represents the bar finite element length.

\subsection{Creep strains}

The creep strains, " $\varepsilon_{\mathrm{c}}(\mathbf{t})$ ", are simulated from the state model proposed by Kawano and Warner [5], and they are obtained by equation 13.

$$
\varepsilon_{c}(t)=\varepsilon_{c d}(t)+\varepsilon_{c v}(t)
$$

$$
\begin{aligned}
& \varepsilon_{c d}(t)=-\frac{1}{E_{o}} \int_{0}^{t} \frac{d \phi_{d}(t, \tau)}{d \tau} \sigma(\tau) d \tau \text { and } \\
& \varepsilon_{c v}(t)=-\frac{1}{E_{o}} \int_{0}^{t} \frac{d \phi_{v}(t, \tau)}{d \tau} \sigma(\tau) d \tau
\end{aligned}
$$

Where " $\varepsilon_{\text {cd }}(t)$ " and " $\varepsilon_{c v}(t)$ " are the deformations parcels due to hardening and visco-elastic effects, respectively. The functions " $\phi_{d}(t, \tau)$ " and " $\phi_{v}(t, \tau)$ " represent their respective creep coefficients. In their incremental versions these parcels are presented in the form:

$$
\Delta \varepsilon_{c d}\left(t_{n}\right)=\frac{1}{E_{o}} \sigma\left(t_{n-1}\right) \cdot\left[\phi_{d}\left(t_{n}, t_{o}\right)-\phi_{d}\left(t_{n-1}, t_{o}\right)\right]
$$

and,

$$
\Delta \varepsilon_{c v}\left(t_{n}\right)=\left[\frac{\phi_{v}^{*}}{E_{o}} \sigma\left(t_{n-1}\right)-\varepsilon_{c v}\left(t_{n-1}\right)\right] \cdot\left[1-e^{-\Delta t_{n} / T_{v}}\right]
$$

with:

$$
\phi_{d}\left(t_{n}, t_{o}\right)=\frac{\left(t_{n}-t_{o}\right)^{0.6}}{10+\left(t_{n}-t_{o}\right)^{0.6}} \cdot \phi_{d}^{*}
$$

and:

$$
\phi_{v}\left(t_{n}, t_{j}\right)=\left[1-e^{-\left(t_{n}-t_{j}\right) / T_{v}}\right] \cdot \phi_{v}^{*}
$$

Where " $\phi_{d}^{*}$ " and " $\phi_{v}^{*}$ " are the asymptotic creep coefficient values for those two parcels, and " $\mathrm{T}_{\mathrm{v}}$ " the retardation time. " $\mathrm{t}_{\mathrm{n}}$ " is the instant for which the creep deformations are being calculated, " $t_{n-1}$ " is the discrete instant, immediately preceding the instant " $\mathrm{n}_{\mathrm{n}}$ ", and " $\mathrm{t}_{\mathrm{o}}$ " is the concrete age at the instant of loading.

At every instant " $t_{n}$ " the creep strains are described according:

$$
\varepsilon_{c}\left(t_{n}\right)=\varepsilon_{c}\left(t_{n-1}\right)+\Delta \varepsilon_{c}\left(t_{n}\right)
$$

Figure 3 - Finite elements: a) Plane Q8; b) bar L3

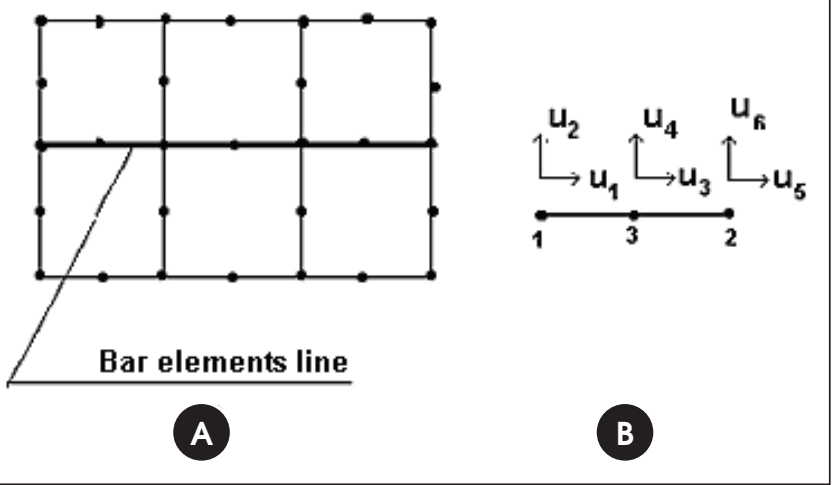


where " $\Delta \varepsilon_{c}\left(t_{n}\right)$ " is the incremental strain and is obtained from:

$$
\Delta \varepsilon_{c}\left(t_{n}\right)=\Delta \varepsilon_{c d}\left(t_{n}\right)+\Delta \varepsilon_{c v}\left(t_{n}\right)
$$

For the purposes of this work is assumed that, during every time interval, the stress magnitudes will remain constant. Its variation over all period of the observation of the phenomenon is expressed in terms of a step kind function.

\section{Computer support}

With a view to the acquisition of the results aimed at the fulfilment of the objectives of this work, it was employed the software named "Análise Constitutiva Não-Linear" - ACNL [8]. Such program was structured according to incremental and iterative procedure and the Finite Elements Method (FEM), on a Nonlinear Orthotropic Formulation in plane state of stresses[7]. It even covers, in its algorithmic framework, the element formulations described in item 2.

\section{Analysed models}

The models studied are columns $\mathbf{3 . 0 0} \mathrm{m}$ length and rectangular cross section $\mathbf{0 . 4 0} \mathrm{m}$ height and base that differs case-by-case, cast in concrete C 40, reinforced with CA-50 A steel bars, figure 4 . The structural member is subjected to a gradual loading process, by the action of a uniform distributed load along the height of the top section, whose magnitude progresses from zero to a final value of $40 \%$ of the ultimate compressive stress of the concrete, table 1 , taking into account the limitations, in terms of stresses, of the NBR 6118/07 creep model.

The analysis was performed on twenty-two cases, distinguished by the cross-sectional dimension, by the reinforcement ratio and the moisture of the environment, as shown in columns 2,3 and 5 , respectively, on table 1 .

The problem domain has been defined from the rectangle whose horizontal dimension is equal to the column length, and the vertical dimension is equal to its cross section height, and its discretization was performed on the basis of plane and bar elements, both 0.10 $\mathrm{m}$ dimensioned, resulting the mesh composed by 120 plane and 60 bar elements, figure 5. It is observed that in this case, as it happens in the figures relating to stress and displacement fields, the structural member is being represented with its longitudinal axis coinciding with the horizontal direction on the plane of the page (" $x$ " direction).

The age of the concrete at the instant of loading was set as 30 days. It was considered that all the perimeter of the column surface is exposed to the environment contact. The retardation time was valued as $T v=600$ days. The asymptotic hardening creep coefficient was considered as being ${\phi_{d}}^{*}=2,00$, as recommended by Kawano and Warner [5]. The asymptotic creep coefficient related to visco-elastic effects, $\phi_{v}{ }^{*}$, exhibit distinct values case to case, table 1 , being obtained by the difference between the total asymptotic creep coefficient of NBR 6118/07 and the asymptotic hardening creep coefficient.

The analysis was performed according to the "Plane State of Stresses".

The chart in figure 6 shows the curves of the creep coefficient evolution with time, drawn from results obtained by the NBR 6118/07 model and the state model adopted in this work. It is noted a good agreement between them, confirming up that the values adopted for the state model parameters were properly fixed.

For the purposes of assessing the creep phenomenon longevity, the maximum age limit of concrete was set as 3000 days, which corresponds to the time from which the creep coefficient, virtually, stabilizes, figure 6 . For the numerical simulation purposes such period of time was discretized from instant observation at 60,120 , $250,500,1000,2000$ and 3000 days.

\section{Program validation}

The program efficiency was checked from the comparison of its results with their corresponding obtained from a simplified algorithm, based on the Solid Mechanics principles. In the design of the latter is considered, above all, the Bernoulli hypothesis according which the sections initially planes remain in this fashion during

Figure 4 - Basic column model

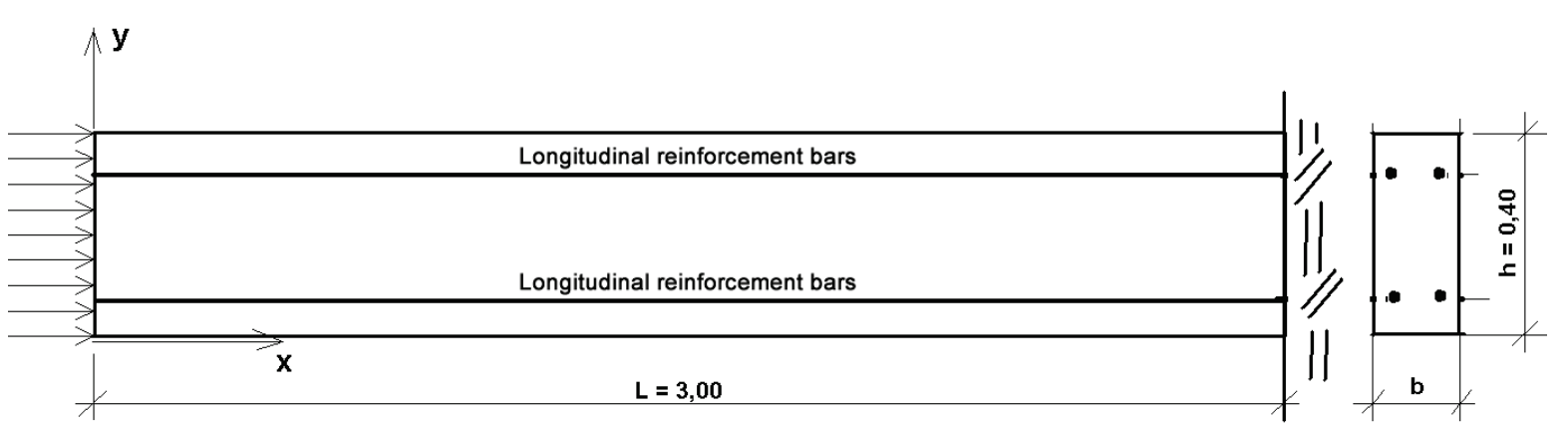


Table 1 - Characterization of the studied cases

\begin{tabular}{|c|c|c|c|c|c|}
\hline Case & $\begin{array}{l}\text { Cross sectional } \\
\text { width }(m)\end{array}$ & $\begin{array}{l}\text { Reinforcement } \\
\text { ratio (\%) }\end{array}$ & Load (kN) & $\begin{array}{c}\text { Environmental } \\
\text { moisture }(\%)\end{array}$ & $\phi^{*} \mathrm{~V}$ \\
\hline 1 & 0.20 & 0.40 & 1320 & 40 & 1.62 \\
\hline 2 & 0.20 & 0.40 & 1320 & 60 & 0.91 \\
\hline 3 & 0.20 & 0.40 & 1320 & 80 & 0.14 \\
\hline 4 & 0.20 & 0.63 & 1340 & 40 & 1.62 \\
\hline 5 & 0.20 & 1.00 & 1388 & 40 & 1.62 \\
\hline 6 & 0.20 & 1.58 & 1444 & 40 & 1.62 \\
\hline 7 & 0.25 & 0.32 & 1644 & 40 & 1.59 \\
\hline 8 & 0.25 & 0.50 & 1665 & 40 & 1.59 \\
\hline 9 & 0.25 & 0.80 & 1700 & 40 & 1.59 \\
\hline 10 & 0.25 & 1.26 & 1764 & 40 & 1.59 \\
\hline 11 & 0.30 & 0.27 & 1962 & 40 & 1.56 \\
\hline 12 & 0.30 & 0.42 & 1988 & 40 & 1.56 \\
\hline 13 & 0.30 & 0.67 & 2029 & 40 & 1.56 \\
\hline 14 & 0.30 & 1.05 & 2083 & 40 & 1.56 \\
\hline 15 & 0.35 & 0.23 & 2280 & 40 & 1.54 \\
\hline 16 & 0.35 & 0.36 & 2310 & 40 & 1.54 \\
\hline 17 & 0.35 & 0.57 & 2346 & 40 & 1.54 \\
\hline 18 & 0.35 & 0.90 & 2408 & 40 & 1.54 \\
\hline 19 & 0.40 & 0.20 & 2604 & 40 & 1.52 \\
\hline 20 & 0.40 & 0.31 & 2626 & 40 & 1.52 \\
\hline 21 & 0.40 & 0.50 & 2668 & 40 & 1.52 \\
\hline 22 & 0.40 & 0.79 & 2724 & 40 & 1.52 \\
\hline
\end{tabular}

Figure 5 - Problem domain and finite element mesh

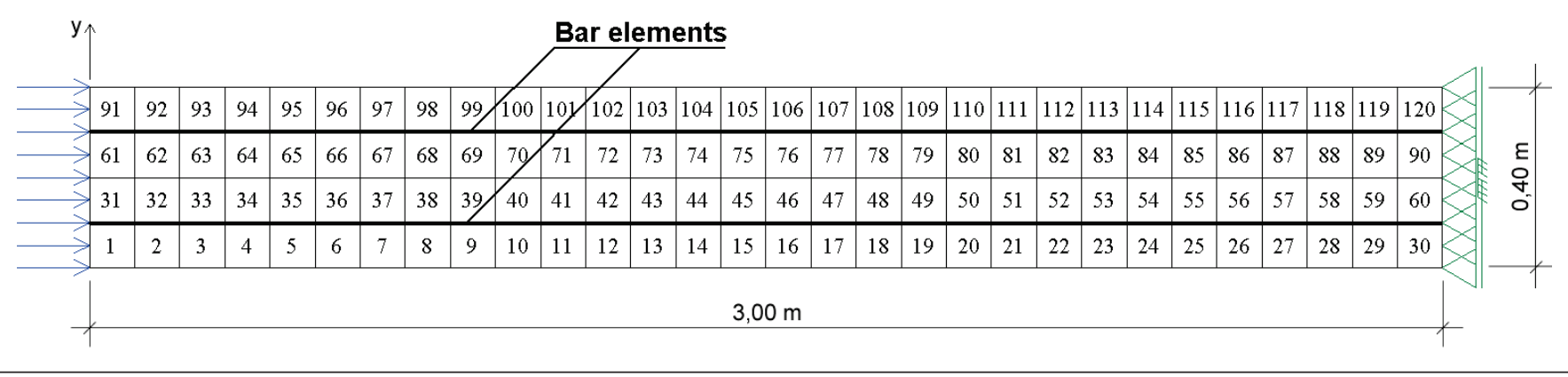

the loading stage and after having achieved the equilibrium for the final load.

In the simplified model the creep strain " $\varepsilon_{\mathrm{f}}\left(\mathbf{t}_{1}, \mathbf{t}_{0}\right)$ " developed between the moment of loading " $t_{0}$ " and the first instant of analysis " $t_{1}$ " is given from:

$$
\varepsilon_{f}\left(t_{1}, t_{0}\right)=\frac{\sigma_{0}}{E_{c}} \phi\left(t_{1}, t_{0}\right)
$$

Where " $\sigma_{o}$ " is the stress on the concrete in the instant of loading, " $E_{c}$ " is the concrete deformation module at 30 days and " $\phi\left(\mathbf{t}_{1}, \mathbf{t}_{\mathrm{o}}\right)$ " is the creep coefficient between the instants " $t_{0}$ " and " $t_{1}$ ". The strain increase " $\Delta \varepsilon_{f}\left(t_{k}, t_{k-1}\right)$ " between the " $t_{k-1}$ " e " $t_{k}$ " time stage will be:

$$
\begin{aligned}
& \Delta \varepsilon_{f}\left(t_{k}, t_{k-1}\right)=\frac{\sigma_{0}}{E_{c}}\left[\phi\left(t_{k}, t_{0}\right)-\phi\left(t_{k-1}, t_{0}\right)\right]+ \\
& \sum_{i=1}^{k-1} \frac{\Delta \sigma_{i}}{E_{c}}\left[\phi\left(t_{k}, t_{i}\right)-\phi\left(t_{k-1}, t_{i}\right)\right]
\end{aligned}
$$

Where " $\Delta \sigma_{i}$ " represents the stress magnitude variation given by: 


$$
\Delta \sigma_{i}=\sigma_{i}-\sigma_{i-1}
$$

In addition, " $\phi\left(\mathbf{t}_{\mathrm{k}}, \mathbf{t}_{\mathrm{i}}\right)$ " is the creep coefficient between any instants " $t_{i}$ " and " $t_{k}$ ". Equations 21 and 22 were corrected with the purpose to consider the steel reinforcement effect, resulting:

$$
\varepsilon_{f, c o r r}\left(t_{l}, t_{o}\right)=\varepsilon_{f}\left(t_{l}, t_{o}\right) \frac{E_{c} A_{c}}{E_{c} A_{c}+E_{s} A_{s}}
$$

and

$$
\Delta \varepsilon_{f, c o r r}\left(t_{k}, t_{k-1}\right)=\Delta \varepsilon_{f}\left(t_{k}, t_{k-1}\right) \frac{E_{c} A_{c}}{E_{c} A_{c}+E_{s} A_{s}}
$$

where the " $E_{c} A_{c}$ " and " $E_{s} A_{s}$ " products represent the concrete and the steel axial stiffness, respectively.

The strains are then obtained from:

$$
\varepsilon_{f}\left(t_{i}\right)=\varepsilon_{f, c o r r}\left(t_{1}, t_{0}\right)+\sum_{k=2}^{i} \Delta \varepsilon_{f, c o r r}\left(t_{k}, t_{k-1}\right)
$$

For the validation purpose were considered the cases 3 and 6 , table 1 , noting up good agreement of results, figure 7 . In case 6 , the differences at 60 days and 3000 days were, exceptionally, the largest, reaching percentages about $4.5 \%$ and $6 \%$, respectively. For the other concrete ages of the case 6 and all ages of the case 3 , the differences did not reach the percentage of $2.5 \%$. The obtained results from the program were comparatively bigger, which can be attributed to the fact that this computational tool take into account, distinctly of the simplified analytical algorithm, the warp-

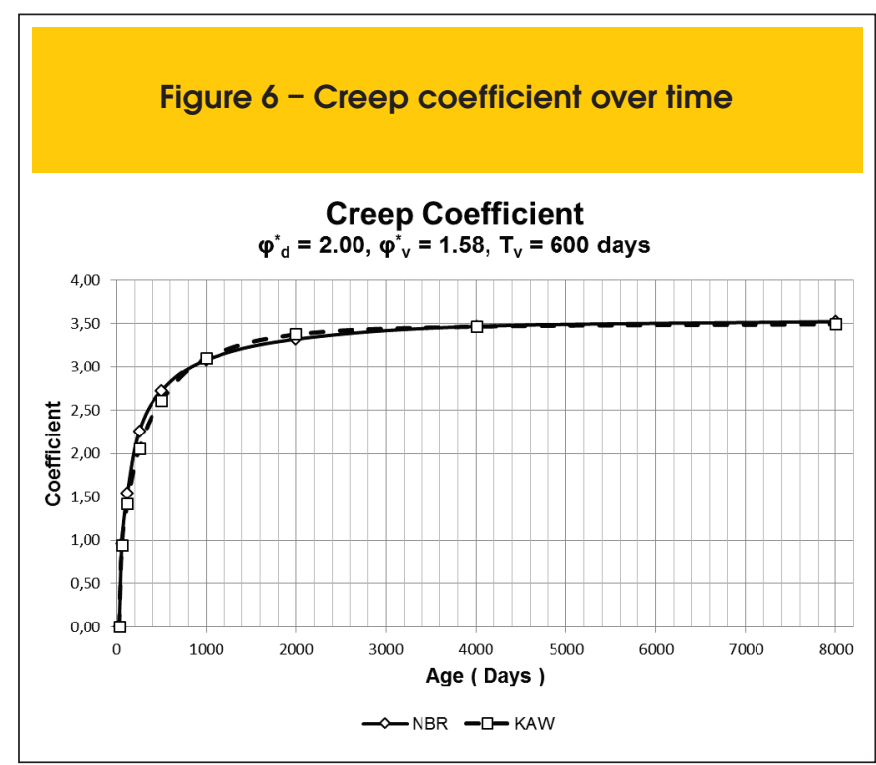

ing of the cross sections, which, indeed, is significant in the column top vicinity, and is intensified during creep deformations.

\section{Results and discussion}

When the equilibrium configuration referring to final load was reached, the axial displacements and normal stresses field took the morphologies shown in figures 8 and 9, respectively. For all studied cases, the displacement magnitude at the top of the column and the stress on the mass of the concrete, were about 1.85 $\mathrm{mm}$ and $16 \mathrm{MPa}$, respectively, table 2 .

By examining the stresses field, figure 9, it may be noted that the overall solid features, shows discrete stress variations, except on the region near its top, which is the loading introduction zone, where it may be observed tenuous disturbance.

The displacement curves over time has showed similar trend, registering the final values given in table 2. For cases 1, 4, 5 and 6 , the creep strains evolved according the curves of figure 10 . At 3000 days the corresponding fields took over distribution similar to that presented in figure 11. The smallest increase of creep displacements was about $3 \mathrm{~mm}$, corresponding to 1.7 times the displacement at the instant of loading that was registered for case 3 , which refers to the highest moisture content. The largest creep displacement was about $5 \mathrm{~mm}$, which is 2.8 times the presented displacement at the instant of loading, that was noted for the case 19 , concerning to the lowest moisture content and the lowest reinforcement ratio.

Due to creep deformations the mass of the concrete experienced stress relief. For cases 1, 4, 5 and 6, the magnitudes evolved in accordance to the curves of figure 12. For the other cases, the curves display similar fashion, differing mainly with regard to its values, table 2. The stresses field have stabilised at 3000 days, showing a similar way as illustrated in figure 13 . The lower stress relief was about $4 \%$, registered in case 19 , while the highest was about $28 \%$, verified to the case 6 , referring to the lowest and highest reinforcement ratio, respectively. It is observed that the creep strains intensified the stress disturbance at the column top region. The stresses on the reinforcement steel bars, in the cases 1, 4, 5 and 6 , evolved according the curves of figure 14, noting up vertiginous increases, after elapsed 3000 days. For the other cases the shapes

Figure 7 - Creep displacement curves over time

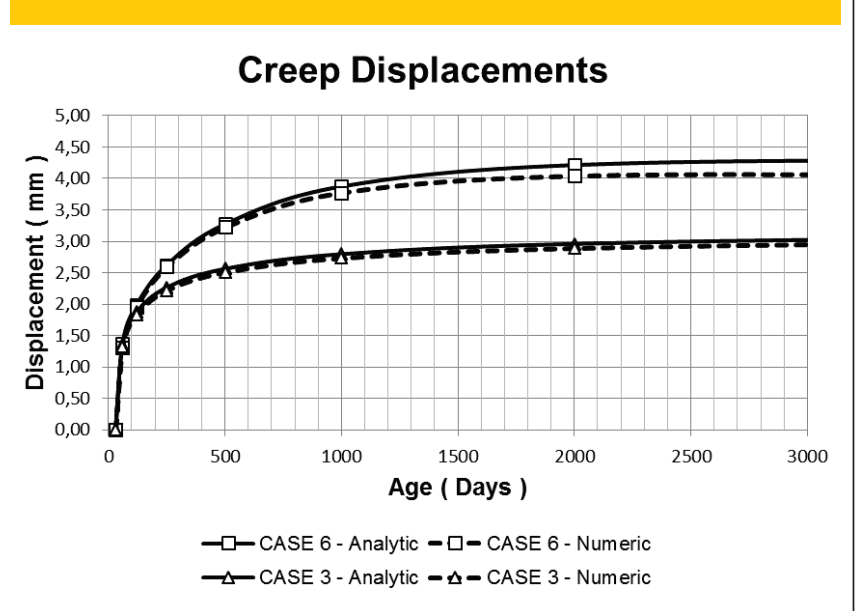


of curves were similar, however, with different magnitudes, table 3 . The smallest overstress was registered to the case 3 , referring to the largest environmental moisture content, whose variation was about $164 \%$, while the largest was observed in case 15 , which corresponds to the lowest reinforcement ratio, culminating in a variation about $277 \%$, table 3 . For cases $1,7,11,12,15,16,19$ and 20 , which are associated with the lowest moisture content and the lowest reinforcement ratio, table 1, ocurrs the proximity of the steel yielding condition, representing imminent risk of the structural member collapse, table 3. From the analysis of the curves in figure 15 , it is noted that the creep displacements on the column top are smaller for larger reinforcement ratios, revealing its strain restraint effect. It should be noted that to reinforcement ratio about $1.58 \%$ the effective creep coefficient final value, that is defined as the ratio between the column shortening due to creep and its value at the instant of loading, was about 2.18 , and, therefore, $40 \%$ lower than their corresponding, evaluated for the concrete with no reinforcement, which is equal to 3.62 , table 4 . With respect to the environmental moisture influence on creep displacements, figure 16, it was showed its inhibiting trend on the phenomenon intensity, given that, for the case of reinforcement ratio about $0.4 \%$ and cross-section $0.20 \mathrm{~m}$ wide, the effective creep coefficient was about 2.73 for moisture content about $40 \%, 2.23$ for moisture content about $60 \%$ and 1.65 , for moisture content about $80 \%$, so that it was observed a reduction of up to $40 \%$ on that parameter value.

\section{Conclusions}

This work refers to the creep strains analysis in reinforced concrete column, on the basis of a state model, from a non-linear orthotropic formulation and the finite element approximation.

In order to the fulfilment of this subject, it was studied some cases differentiated among themselves by the adopted reinforcement and the environmental moisture content.

The obtained results showed that for the environmental conditions adopted and the parameters of the cases analysed, the creep strains virtually stabilises themselves at 3000 days of the concrete age.

Furthermore, it was noted the occurrence of stress relief in the con-

\section{Figure 8 - Longitudinal displacement field at the instant of loading - Case 1}

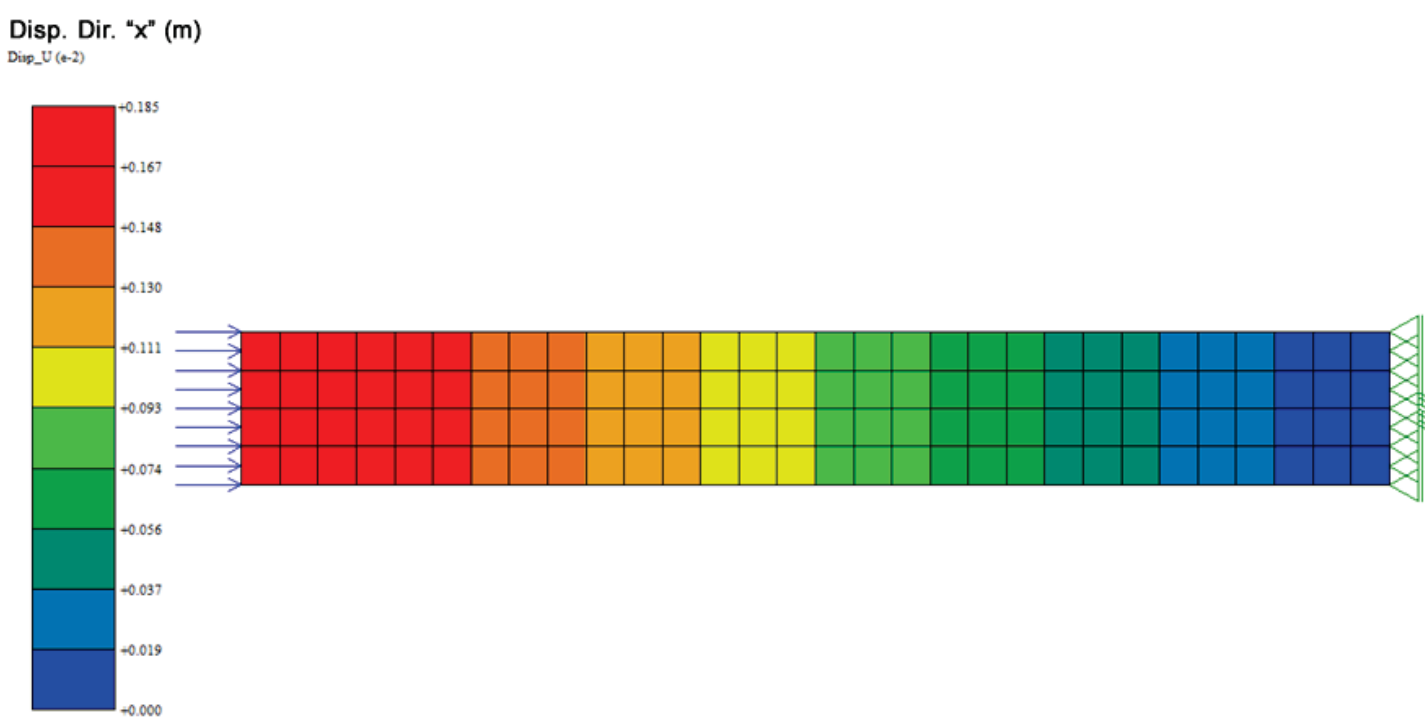

Figure 9 - Normal stress field at the instant of loading - Case 14

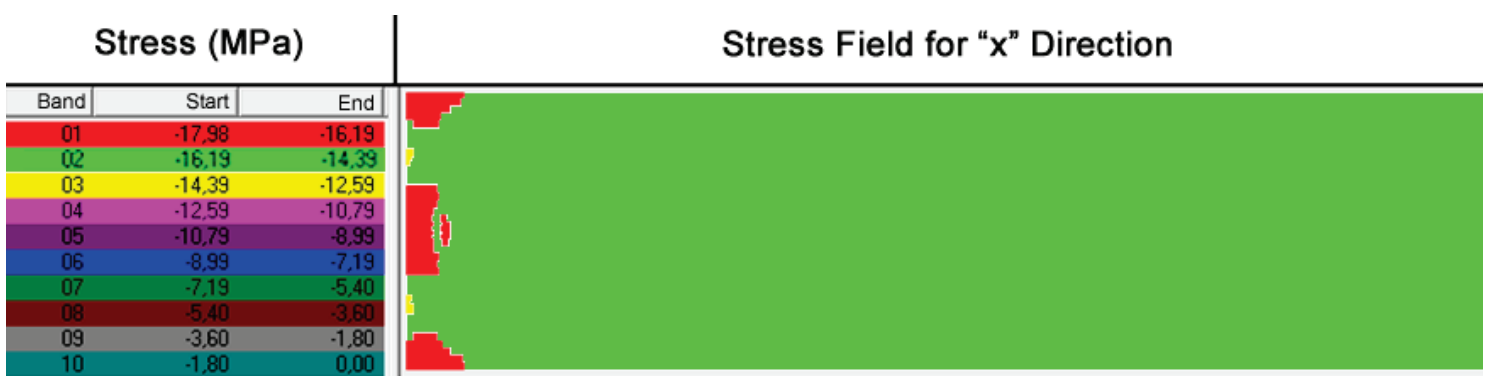


Table 2 - General results

\begin{tabular}{|c|c|c|c|c|c|c|}
\hline \multirow{2}{*}{ Case } & \multicolumn{2}{|c|}{ Displacement (mm) } & \multicolumn{2}{|c|}{ Stress on concrete (MPa) } & \multicolumn{2}{|c|}{ Stress increase } \\
\hline & Immediate & Creep (3000 days) & Immediate & Creep (3000 days) & Total (MPa) & Percentage \\
\hline 1 & 1.85 & 5.06 & 16.0 & 14.6 & 1.4 & 8.8 \\
\hline 2 & 1.85 & 4.13 & 16.0 & 14.9 & 1.1 & 6.9 \\
\hline 3 & 1.85 & 3.04 & 16.0 & 15.2 & 0.8 & 5.0 \\
\hline 4 & 1.85 & 4.81 & 15.9 & 13.9 & 2.0 & 13.3 \\
\hline 5 & 1.86 & 4.51 & 16.1 & 12.9 & 3.2 & 19.9 \\
\hline 6 & 1.86 & 4.06 & 16.0 & 11.5 & 4.5 & 28.1 \\
\hline 7 & 1.86 & 5.11 & 16.0 & 14.9 & 1.1 & 6.9 \\
\hline 8 & 1.85 & 4.92 & 16.0 & 14.3 & 1.7 & 10.6 \\
\hline 9 & 1.85 & 4.62 & 16.0 & 13.4 & 2.6 & 16.3 \\
\hline 10 & 1.86 & 4.26 & 16.0 & 12.3 & 3.7 & 23.1 \\
\hline 11 & 1.85 & 5.13 & 16.0 & 15.1 & 0.9 & 5.6 \\
\hline 12 & 1.86 & 4.98 & 16.0 & 14.6 & 1.4 & 8.8 \\
\hline 13 & 1.86 & 4.74 & 16.0 & 13.9 & 2.1 & 13.1 \\
\hline 14 & 1.85 & 4.39 & 16.0 & 12.8 & 3.2 & 20 \\
\hline 15 & 1.85 & 5.13 & 16.0 & 15.2 & 0.8 & 5.0 \\
\hline 16 & 1.86 & 5.01 & 16.0 & 14.8 & 1.2 & 7.5 \\
\hline 17 & 1.85 & 4.79 & 16.0 & 14.1 & 1.9 & 11.9 \\
\hline 18 & 1.86 & 4.50 & 16.0 & 13.2 & 2.8 & 17.5 \\
\hline 19 & 1.85 & 5.14 & 16.0 & 15.3 & 0.7 & 4.4 \\
\hline 20 & 1.85 & 5.02 & 16.0 & 15.0 & 1.0 & 6.3 \\
\hline 21 & 1.86 & 4.84 & 16.0 & 14.4 & 1.6 & 10.0 \\
\hline 22 & 1.85 & 4.57 & 16.0 & 13.5 & 2.5 & 15.6 \\
\hline
\end{tabular}

crete according to values as greater as higher the adopted reinforcement ratio, agreeing with the trend reported in [4].

The analysis object of this study even pointed out the occurrence of stress increase on the steel bars that, for lower reinforcement

Figure 10 - Creep displacement curves for $20 \mathrm{~cm} \mathrm{x} 40 \mathrm{~cm}$ sections and $40 \%$ moisture content

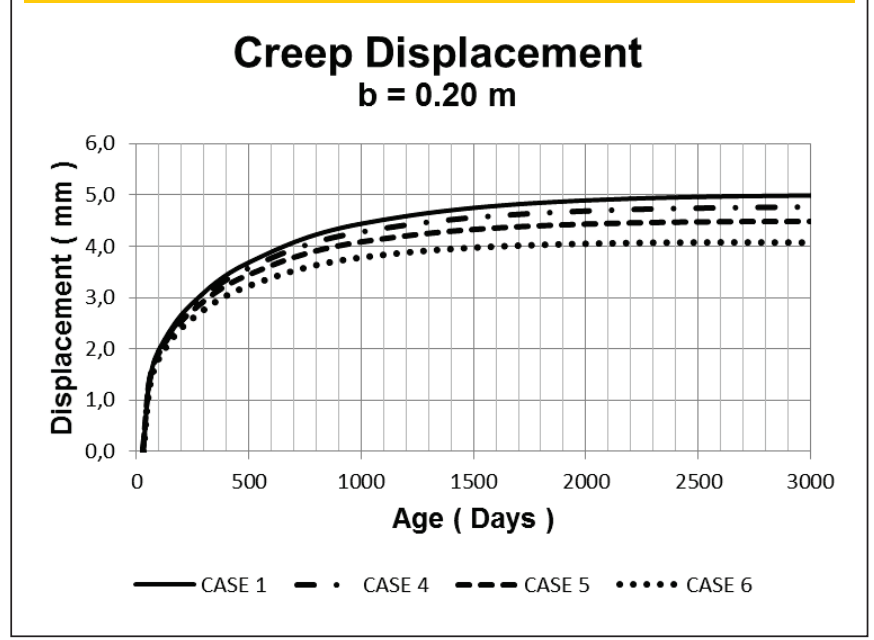

ratio cases, culminated with the approach of the material yielding condition, although this aspect has not been reported in [4].

In addition, it was observed that the effective creep coefficient, defined as the ratio between the column shortening due to creep and the observed contraction at the instant of loading, assumed values as lower as higher the reinforcement ratio, thus confirming its effect of deformation restraint.

The obtained results corroborated the trend reported by the scientific literature on the subject, with regard to the moisture content influence on the creep effect, since the related deformation observed was as higher as smaller the value of this parameter.

\section{Acknowledgements}

This report is part of a research work on the numerical simulation of the creep strains on reinforced concrete members supported by the Fundação Coordenação de Aperfeiçoamento de Pessoal de Nível Superior - CAPES and by the Pró-Reitoria de Pesquisa da Universidade Federal do Rio Grande do Norte - UFRN. Their support is gratefully acknowledged.

\section{References}

[01] ASSOCIAÇÃO BRASILEIRA DE NORMAS TÉCNICAS. NBR 6118: Projeto de Estruturas de Concreto Procedimento. Rio de Janeiro: ABNT, 2007. 
Figure 11 - Longitudinal displacement field due to creep at 3000 days - Case 19

$$
\underset{\text { Disp_U ((t-2) }}{\text { Dir. " } \mathrm{x} \text { " (m) }}
$$

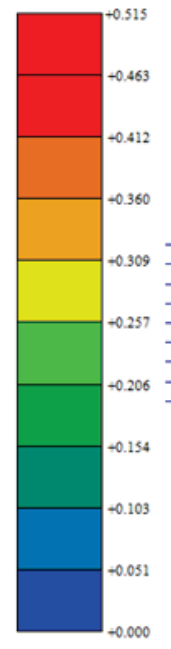

Figure 12 - Evolution of stresses in the concrete for $20 \mathrm{~cm} \times 40 \mathrm{~cm}$ sections and $40 \%$ moisture content

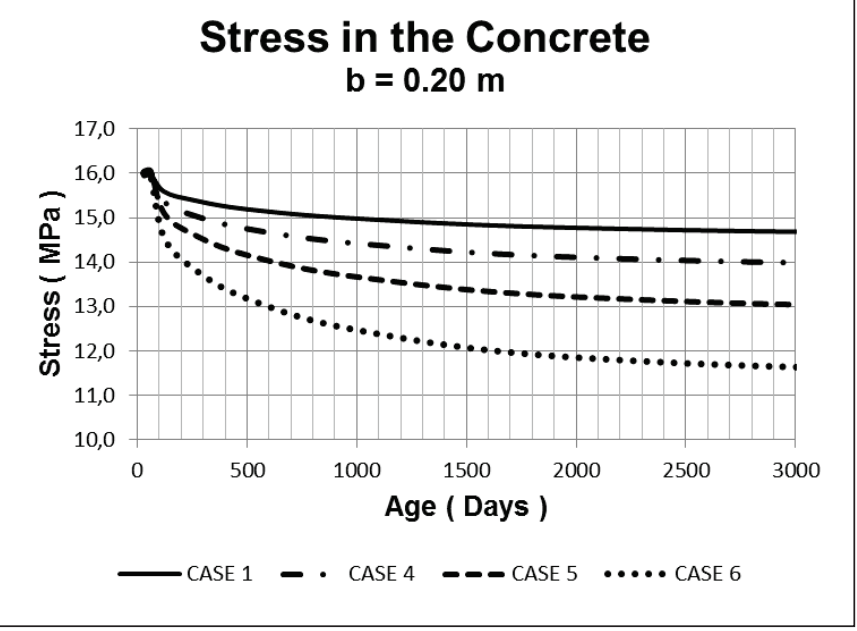

[02] COMITE EURO-INTERNACIONAL DU BETON. CEB-FIP Model Code 1990: Design Code. Thomas Telford, Londres, 1993.

[03] HOGNESTAD, E. A Study of Combined Bending and Axial Load in Reinforced Concrete Members. University of Illinois, Engineering Experiment Station, Bolletin n. 399, Urbana, Illinóis, Vol. 49, n 22, 1951.

[04] KATAOTA, L.T.; MACHADO, M.A.S.; BITTENCOURT, T.N. Análise Numérica da Transferência de Carga do Concreto para a Armadura em Pilares de Concreto Armado Devida à Fluência e Retração. In: CONGRESSO BRASILEIRO DE CONCRETO, 52, 2010. Fortaleza. Anais... Fortaleza: IBRACON, 2010.

[05] KAWANO, A.; WARNER, R.F. Model Formulations for Numerical Creep Calculations for Concrete. Journal of Structural Engineering, [S.I.], vol. 122, n. 3, p. 284-290, 1996.

[06] KUPFER, H.B.; GERSTLE, K.H. Behaviour of Concrete under Biaxial Stresses. Journal of Engineering Mechanics, [S.I.], vol. 99, n. 4, p. 853-866, 1973.

[07] KWAK, H.G.; FILIPPOU, F.C. Finite Elements Analysis

Figura 13 - Normal stress field in the concrete at 3000 days - Case 6

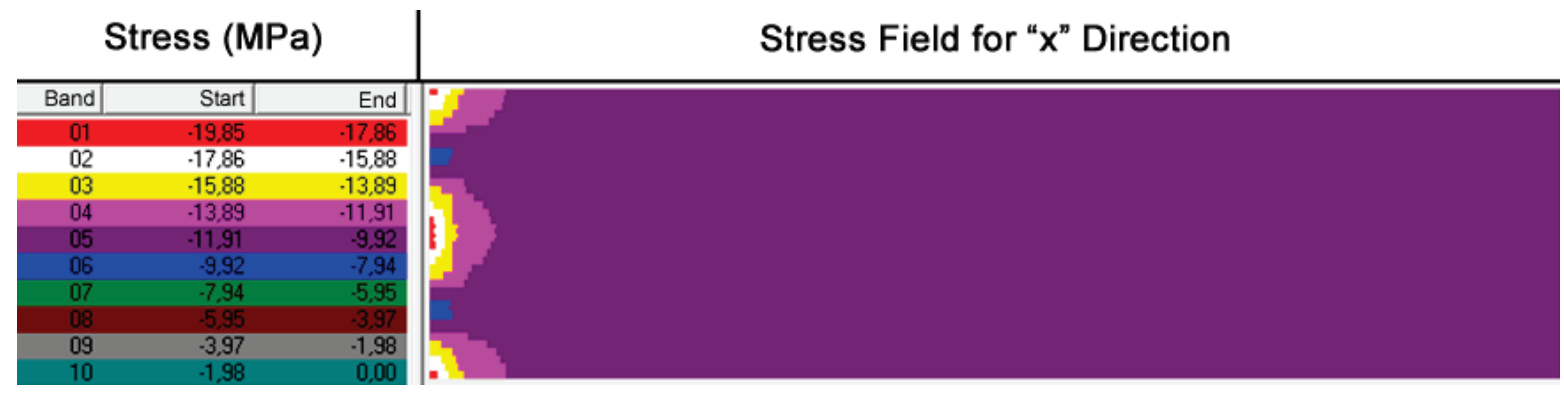


Table 3 - Normal stresses on the reinforcement steel bars

\begin{tabular}{|c|c|c|c|c|}
\hline \multirow{2}{*}{ Case } & \multicolumn{2}{|c|}{ Stress in the reinforcement (MPa) } & \multicolumn{2}{|c|}{ Stress increase } \\
\hline & Initial & Final (3000 days) & Total (MPa) & Percentage \\
\hline 1 & 129.4 & 482.2 & 352.8 & 272.7 \\
\hline 2 & 129.4 & 417.4 & 288.0 & 222.6 \\
\hline 3 & 129.4 & 342.0 & 212.7 & 164.4 \\
\hline 4 & 129.0 & 464.3 & 335.3 & 259.9 \\
\hline 5 & 130.0 & 442.8 & 312.8 & 240.6 \\
\hline 6 & 129.6 & 409.1 & 279.5 & 215.7 \\
\hline 7 & 129.8 & 486.6 & 356.9 & 275.0 \\
\hline 8 & 129.6 & 472.3 & 342.8 & 264.5 \\
\hline 9 & 129.2 & 450.4 & 321.2 & 248.5 \\
\hline 10 & 129.6 & 423.9 & 294.3 & 227.1 \\
\hline 11 & 129.6 & 487.9 & 358.4 & 276.6 \\
\hline 12 & 129.8 & 477.2 & 347.4 & 267.7 \\
\hline 13 & 129.9 & 459.9 & 330.0 & 254.0 \\
\hline 14 & 129.5 & 434.3 & 304.7 & 235.3 \\
\hline 15 & 129.4 & 488.2 & 358.8 & 277.2 \\
\hline 16 & 129.9 & 479.9 & 350.0 & 269.5 \\
\hline 17 & 129.7 & 463.7 & 334.0 & 257.6 \\
\hline 18 & 129.8 & 442.7 & 312.8 & 240.9 \\
\hline 19 & 129.7 & 489.1 & 359.4 & 277.1 \\
\hline 20 & 129.6 & 480.1 & 350.5 & 270.4 \\
\hline 21 & 129.8 & 467.1 & 337.3 & 259.9 \\
\hline 22 & 129.6 & 447.1 & 317.5 & 245.1 \\
\hline
\end{tabular}

\begin{tabular}{|c|c|c|c|c|c|}
\hline \multirow{3}{*}{ Case } & \multicolumn{4}{|c|}{ Table 4 - Longitudinal displacement on the column top } & \\
\hline & \multicolumn{2}{|c|}{ Displacement (mm) } & \multicolumn{3}{|c|}{ Creep coefficient } \\
\hline & Initial & Creep (3000 days) & Effective & NBR & Difference (\%) \\
\hline 1 & 1.85 & 5.06 & 2.73 & 3.62 & 24.5 \\
\hline 2 & 1.85 & 4.13 & 2.23 & 2.91 & 23.5 \\
\hline 3 & 1.85 & 3.04 & 1.65 & 2.14 & 23.1 \\
\hline 4 & 1.85 & 4.81 & 2.61 & 3.62 & 28.0 \\
\hline 5 & 1.86 & 4.51 & 2.42 & 3.62 & 33.1 \\
\hline 6 & 1.86 & 4.06 & 2.18 & 3.62 & 39.7 \\
\hline 7 & 1.86 & 5.11 & 2.76 & 3.59 & 23.2 \\
\hline 8 & 1.85 & 4.92 & 2.65 & 3.59 & 26.0 \\
\hline 9 & 1.85 & 4.62 & 2.50 & 3.59 & 30.4 \\
\hline 10 & 1.86 & 4.26 & 2.29 & 3.59 & 36.1 \\
\hline 11 & 1.85 & 5.13 & 2.77 & 3.56 & 22.2 \\
\hline 12 & 1.86 & 4.98 & 2.68 & 3.56 & 24.6 \\
\hline 13 & 1.86 & 4.74 & 2.55 & 3.56 & 28.4 \\
\hline 14 & 1.85 & 4.39 & 2.37 & 3.56 & 33.4 \\
\hline 15 & 1.85 & 5.13 & 2.78 & 3.54 & 21.5 \\
\hline 16 & 1.86 & 5.01 & 2.70 & 3.54 & 23.6 \\
\hline 17 & 1.85 & 4.79 & 2.58 & 3.54 & 26.9 \\
\hline 18 & 1.86 & 4.50 & 2.42 & 3.54 & 31.5 \\
\hline 19 & 1.85 & 5.14 & 2.77 & 3.52 & 21.1 \\
\hline 20 & 1.85 & 5.02 & 2.71 & 3.52 & 23.0 \\
\hline 21 & 1.86 & 4.84 & 2.61 & 3.52 & 25.9 \\
\hline 22 & 1.85 & 4.57 & 2.46 & 3.52 & 30.0 \\
\hline
\end{tabular}


of Reinforced Concrete Structures Under Monotonic Loads. Report UCB/SEMM-90/14, Berkeley, Califórnia, 1990.

[08] MADUREIRA, E.L. Simulação Numérica do

Comportamento Mecânico de Elementos de Concreto Armado Afetados pela Reação Álcali-Agregado. 2007. Tese (Doutorado em Engenharia Civil) - Departamento de Engenharia Civil - Universidade Federal de Pernambuco, Recife, 2007.

[09] NGO, D.; SCORDELIS, A.C. Finite Element Analysis of Reinforced Concrete Beams. Journal of $\mathrm{ACl}$, [S.I.], vol. 64, n. 3, p. 152-163, 1967.
Figure 14 - Evolution of stresses in the reinforcement for $20 \mathrm{~cm} \times 40 \mathrm{~cm}$ sections and $40 \%$ moisture content

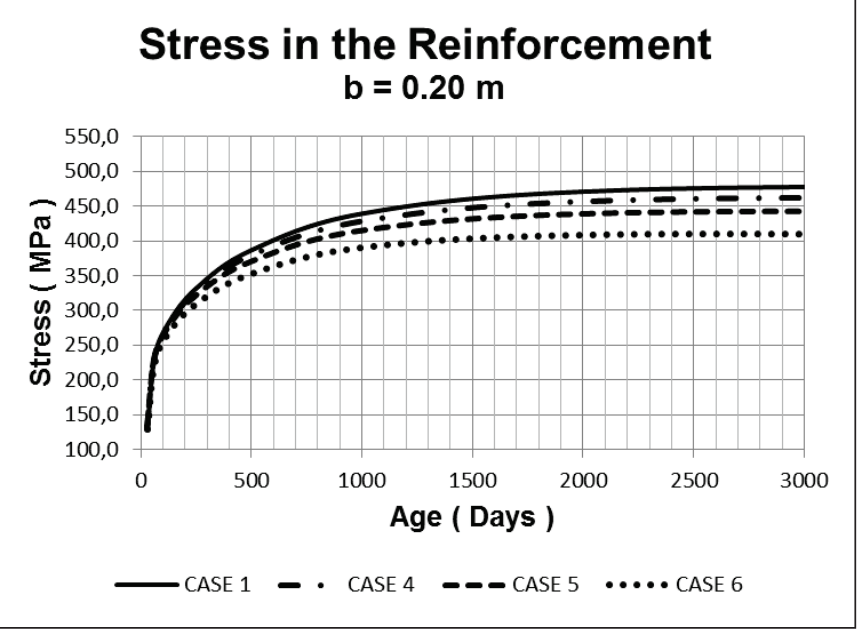

Figure 15 - Creep displacements according the reinforcement ratio for $40 \%$ moisture content

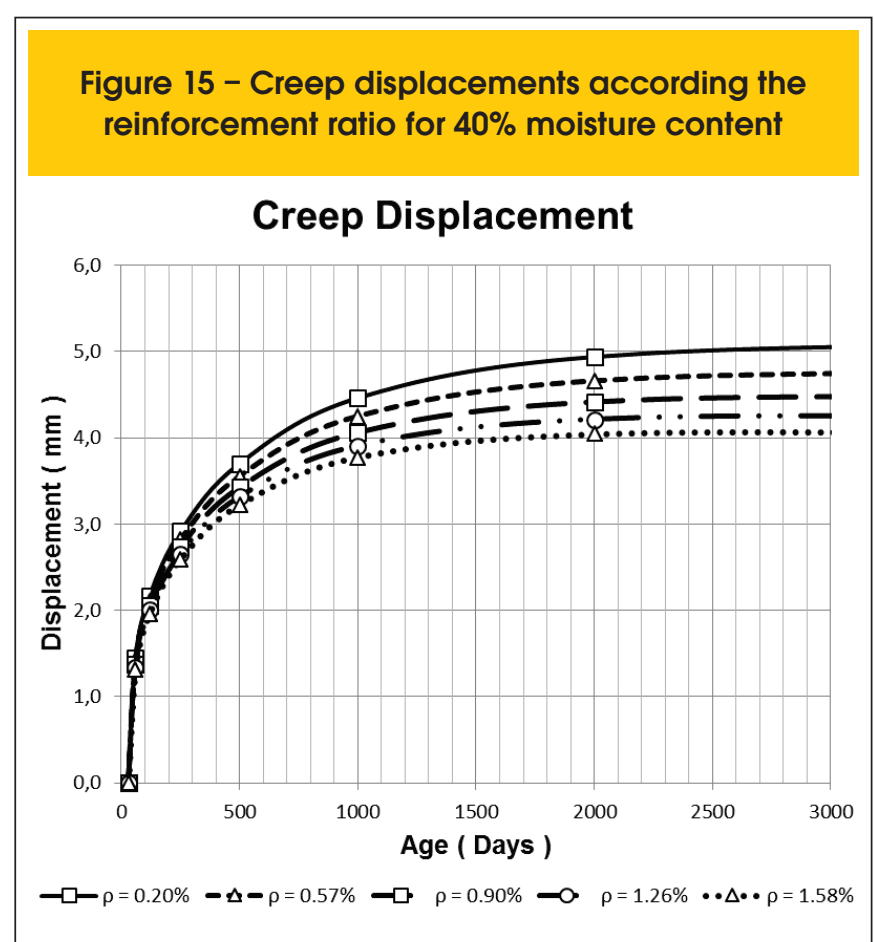

Figure 16 - Creep displacements according the environmental moisture for $0.40 \%$ reinforcement ratio

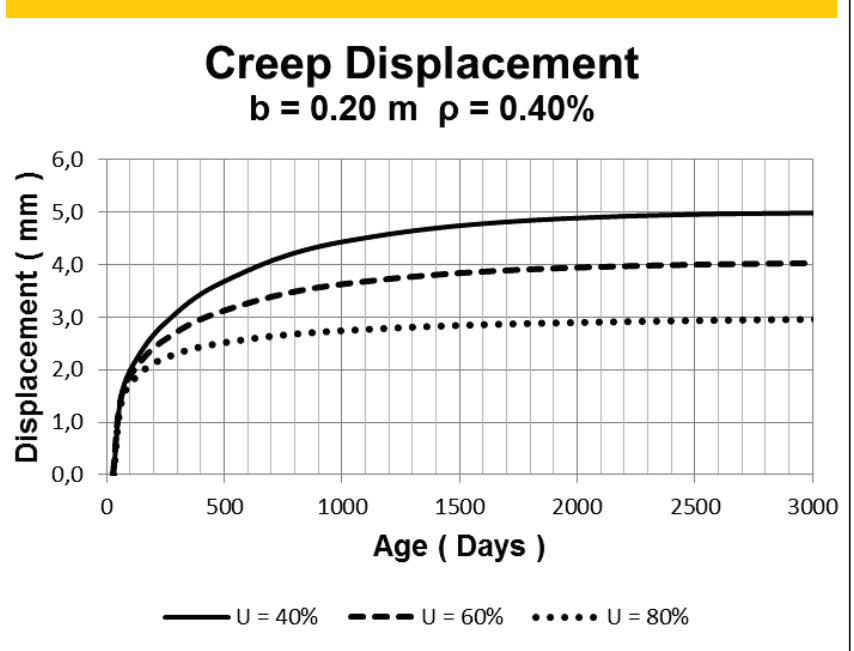

